\title{
Ordering policies of a deteriorating item in an EOQ model with backorder under two- level partial trade credit
}

\begin{abstract}
In the classical inventory model, it was assumed that the retailer must settle the accounts of the purchased items as soon as they are received. In practice, however, the supplier usually offers a full or partial delay period to the retailer to pay for the amount of the purchasing costs. In the partial trade credit contract, which is mostly applied to avoid non-payment risks, the retailer must pay for a portion of the purchased goods at the time of ordering and may delay settling the rest until the end of the predefined agreed upon period, so-called credit period. This paper assumes a two-level partial trade credit where both supplier and retailer offer a partial trade credit to their downstream members. The objective here is to determine the retailerôs ordering policy of a deteriorating item by formulating his economic order quantity (EOQ) inventory system with backorder as a cost minimization problem. The sensitivity of the variables on different parameters has been also analyzed by applying numerical examples.
\end{abstract}

Keyword: EOQ; Inventory system; Partial trade credit; Permissible delay in payment; Twolevel trade credit 